\title{
EVALUASI SISTEM MANAJEMEN KESELAMATAN DAN KESEHATAN KERJA DI RSUD MOH. ANWAR SUMENEP
}

\author{
Laylatul Hasanah \\ Universitas Wiraraja Sumenep
}

\begin{abstract}
ABSTRAK
Keselamatan dan kesehatan kerja memiliki filosofi sebagai suatu pokok upaya untuk menjamin kebaikan baik secara fisik atau non fisik karyawan serta budaya menuju masyarakat yang sejahtera. Menurut ilmunya yakni merupakan pengetahuan dan penerapan dalam suatu bentuk usaha agar tidak terjadi kecelakaan serta penyakit yang diakibatkan oleh pekerjaan. Kesehatan dan keselamatan kerja memang tidak dapat dipisahkan dari proses produksi serta jasa maupun di industri. (Abdul Rohman, 2017).

Pelaksanaan penerapan keselamatan dan kesehatan kerja sudah mulai menjadi hal yang dirasa penting baik bagi pasien, keluarga pasien, tamu yang berkunjung, atau pelanggan yang berasal dari internal serta steakholder dari rumah sakit lainnya. Manajemen keselamatan dan kesehatan kerja mulai dikembangkan keberadaannya dalam rangka untuk meminimalisir terjadinya kecelakaan dan penyakit akibat kerja dirumah sakit. (Kun, 2017)

Tujuan penelitian untuk mengetahui penerapan dalam system manajemen keselamatan dan kesehatan kerja. Metode penelitian bersifat deskriptif bersifat observasional karena melakukan pengamatan di lapangan. Ditinjau dari tempat penelitian termasuk penelitian lapangan karena mendapatkan data primer dari pengukuran, wawancara dan observasi di tempat kerjaBerdasarkan waktudigunakan penelitian ini merupakan penelitian cross sectional. Hasil penelitian menunjukkan dengan pengetahuan komitmen dan kebijakan kurang 68,75\%, perencanaan kurang $43,75 \%$, penerapan kurang $43,75 \%$, pengukuran dan evaluasi $50 \%$,tinjauan ulang manajemen $56,25 \%$. Kesimpulan pengetahuan tentang penerapan keselamatan dan kesehatan kerja di rumah sakit Moh.Anwar kurang.
\end{abstract}

\section{Kata Kunci : Evaluasi; Penerapan; Keselamatan dan Kesehatan Kerja; Rumah Sakit}

\section{ABSTRACT}

The safety and work health have a philosophy as a subject an effort to ensure good either physically or non physical culture to employees and prosperous society.According to its science knowledge and the application of which is in a form of business activities to not the case of accidents and diseases caused by work. Health and safety at work are not separated from the production process and services as well as in the industry. The implementation of the application of work safety and health have started to become is considered necessary to better for patients, family patients, guests visit, or subscriber derived from internal and steakholder of other hospitals .Management work safety and health begins to develop its existence in order to minimize the accident and disease caused by work home hospital. The purpose of research to know the application of management in system work safety and health .Research methodology is descriptive is observational for doing of the field observation. In terms of place research including research the court for get the data of the primary, interviews and observation at work. Based on the time of used the research is research cross sectional. The result researchshow thatless knowledgeof the commitment 68,75\% policy, 43,75\% less planning, lessofapplication 43,75\%, 50 percent of the measurement and evaluation, a review 56,25\% management .the conclusionof knowledge about the application of the occupational health and safety in the hospital moh. Anwar less.

\section{Keywords : Evaluation; Practice; The Safety and Work Health; Hospital}

\section{PENDAHULUAN}

Keselamatan dan kesehatan kerja memiliki filosofi sebagai suatu pokok upaya untuk menjamin kebaikan baik secara fisik atau non fisik karyawan serta budaya menuju masyarakat yang sejahtera. Menurut ilmunya yakni merupakan pengetahuan dan penerapan dalam suatu bentuk usaha agar tidak terjadi kecelakaan serta penyakit yang diakibatkan oleh pekerjaan. Kesehatan dan keselamatan kerja memang tidak dapat dipisahkan dari proses produksi serta jasa maupun di industri. (Abdul Rohman, 2017). Kecelakaan yakni suatu kejadian yang tidak terduga serta dapat menjadi sebab adanya cedera atau kerusakan, kecelakaan dapat terjadi karena kelalaian dari tempat usaha dan karyawan, karena hal tersebut dapat memunculkan trauma bagi dua pihak. Cedera yang ditimbulkan oleh kecelakaan kerja dapat mempengaruhi kehidupan pribadi, keluarga, dan kualitas hidup karyawan tersebut. Bagi tempat usaha, akan terjadi kerugian produksi akibat waktu yang terbuang pada saat dilakukan pemantauan atau kecelakaan tersebut serta adanya biaya untuk dilakukan proses hokum atas kecelakaan tersebut. (Ridley, 2008). Berdasarkan PER.05/MEN/1996 pasal 
1, Sistem Manajemen Keselamatan dan Kesehatan Kerja (SMK3) merupakan sistem yang seluruh manajemennya yang terdiri dari perencanaan, implementasi, prosedur, SDM yang dibutuhkan untuk mengembangkan penerapan demi pencapaian dan pemeliharaan yang berkaitan dengan K3 dalam rangka untuk mengendalikan risiko yang memiliki keterkaitan dengan segala kegiatan demi terciptanya lingkungan kerja yang nyaman, efektif, serta efisien. (Suardi, 2007). Menurut peraturan menteri kesehatan republik Indonesia nomor 66 tahun 2016 tentang keselamatan dan kesehatan kerja rumah sakit bahwa "Rumah Sakit adalah institusi pelayanan kesehatan yang menyelenggarakan pelayanan kesehatan perorangan secara paripurna yang menyediakan pelayanan rawat inap, rawat jalan, dan gawat darurat

Rumah Sakit mempunyai tugas memberikan pelayanan kesehatan perorangan secara paripurna." Serta menurut pasal undang-undang tahun 2009 "Rumah Sakit mempunyai fungsi sebagai penyelenggara pelayanan pengobatan dan pemulihan kesehatan sesuai dengan standar pelayanan rumah sakit, pemelihara dalam meningkatkan kesehatan perorangan melalui pelayanan kesehatan yang paripurna tingkat kedua dan ketiga sesuai kebutuhan medis, penyelenggara pendidikan dan pelatihan sumber daya manusia dalam rangka peningkatan kemampuan dalam pemberian pelayanan kesehatan, penyelenggara penelitian dan pengembangan serta penapisan teknologi bidang kesehatan dalam rangka peningkatan pelayanan kesehatan dengan memperhatikan etika ilmu pengetahuan bidang kesehatan. Pelaksanaan penerapan keselamatan dan kesehatan kerja sudah mulai menjadi hal yang dirasa penting baik bagi pasien, keluarga pasien, tamu yang berkunjung, atau pelanggan yang berasal dari internal serta steakholder dari rumah sakit lainnya. Manajemen keselamatan dan kesehatan kerja mulai dikembangkan keberadaannya dalam rangka untuk meminimalisir terjadinya kecelakaan dan penyakit akibat kerja dirumah sakit. (Kun, 2017)

\section{METODE PENELITIAN}

Penelitian ini adalah deskriptif bersifat observasional karena melakukan pengamatan di lapangan. Ditinjau dari tempat penelitian termasuk penelitian lapangan karena mendapatkan data primer dari pengukuran, wawancara dan observasi di tempat kerjaBerdasarkan waktudigunakan penelitian ini merupakan penelitian cross sectional.

\section{HASIL}

\section{Komiten dan Kebijakan}

Distribusi tenaga kerja untuk variabel komitmen dan kebijakan dari tim panitia pembina Keselamatan dan Kesehatan yang (P2K3) berjumlah 16 orang
Tabel 1

Distribusi Tenaga Kerja Berdasarkan

Pengetahuan Tentang Variabel Komitmen Dan Kebijakan

\begin{tabular}{|c|c|c|}
\hline Kriteria & $\sum$ Tim K3 & \% \\
\hline Baik & 2 & 12,5 \\
\hline Cukup & 3 & 18,75 \\
\hline Kurang & 11 & 68,75 \\
\hline
\end{tabular}

Hasil dari rekapitulasi data penerapan SMK3 di RSUD. Tahun 2013 untuk variabel komitmen dan kebijakan dari 16 Tenaga Kerja tim K3 dengankriteria baik 2 responden $(12,5 \%)$ dengan kriteria cukup 3 responden $(18,75 \%)$ untuk kriteria kurang sebanyak 11 orang $(68,75 \%)$.

\section{Perencanaan}

Tenaga kerja untuk variabel perencanaan dari tim panitia pembina Keselamatan dan Kesehatan yang (P2K3) berjumlah 16 orang.

Tabel 2

Distribusi tenaga kerja tentang pengetahuan perencanaan

\begin{tabular}{|c|c|c|}
\hline Kriteria & $\sum$ tim K3 & \% \\
\hline Baik & 2 & 12,5 \\
\hline Cukup & 7 & 43,75 \\
\hline Kurang & 7 & 43,75 \\
\hline
\end{tabular}

Hasil dari rekapitulasi data penerapan SMK3 di RSUD. Tahun 2013 Sumenep untuk variablePerencanaan dari 16 tenaga kerja tim K3 dengan kriteria baik 2 responden $(12,5 \%)$ dengan kriteria cukup 7 responden $(43,75 \%)$ untuk kriteria kurang sebanyak 7 orang $(43,75 \%)$.

\section{Penerapan}

Distribusi tenaga kerja untuk variabel penerapan dari tim panitia pembina Keselamatan dan Kesehatan yang (P2K3) berjumlah 16 orang.

Tabel 3

Distribusi tenaga kerja tentang pengetahuan penerapan

\begin{tabular}{|c|c|c|}
\hline Kriteria & $\sum$ tim K3 & \% \\
\hline Baik & 2 & 12,5 \\
\hline Cukup & 7 & 43,75 \\
\hline Kurang & 7 & 43,75 \\
\hline
\end{tabular}

Hasil dari rekapitulasi data penerapan SMK3 di RSUD. Tahun 2013 untuk variabel Penerapan 16 tenaga kerja tim K3 kriteria baik sebanyak 2 responden $(12,5 \%)$ dengan kriteria cukup sebanyak 7 orang $(43,75 \%)$ dengan kriteria kurang 7 responden $(43,75 \%)$ 


\section{Pengukuran dan Evaluasi}

Distribusi tenaga kerja untuk variabel pengukuran dan evaluasi dari tim panitia pembina Keselamatan dan Kesehatan yang (P2K3) berjumlah 16 orang.

Tabel 4

Distribusi tenaga kerja tentang pengetahuan pengukuran dan evaluasi

\begin{tabular}{|c|c|c|}
\hline Kriteria & $\sum$ tim K3 & \% \\
\hline Baik & 2 & 6,25 \\
\hline Cukup & 6 & 37,5 \\
\hline Kurang & 8 & 50 \\
\hline
\end{tabular}

Hasil dari rekapitulasi data penerapan SMK3 untuk variabel Pengukuran dan Evaluasi dari 16 Tenaga Kerja tim K3 kriteria baik sebanyak 2 orang $(12,5 \%)$ dengan kriteria cukup sebanyak 6 responden $(37,5 \%)$ dengan kriteria kurang sebanyak 8 responden $(50 \%)$.

\section{Tinjauan Ulang Manajemen}

Distribusi tenaga kerja untuk variabel tinjauan ulang manajemen dari tim panitia pembina Keselamatan dan Kesehatan yang (P2K3) berjumlah 16 orang.

\section{Tabel 5}

Distribusi tenaga kerja tentang pengetahuan tinjauan ulang

\begin{tabular}{|c|c|c|}
\hline Kriteria & $\sum$ tim K3 & \% \\
\hline Baik & 2 & 12,5 \\
\hline Cukup & 5 & 31,25 \\
\hline Kurang & 9 & 56,25 \\
\hline
\end{tabular}

Hasil dari rekapitulasi data penerapan SMK3 untuk variabel Tinjauan Ulang dari 16 Tenaga Kerja tim K3 kriteria baik sebanyak 2 orang (12,5\%) dengan kategori cukup sebanyak 5 responden (31,25\%) dengan kategori kurang sebanyak 9 reponden $(56,25 \%)$.

\section{PEMBAHASAN}

Kegiatan yang dilakukan oleh tim K3 dan P2K3 meliputi kegiatan membuat komitmen dan kebijakan, perencanaan $\mathrm{K} 3$, menerapkan hasil perencanaan $\mathrm{K} 3$, melakukan pengukuran dan evaluasi pada hasil penerapan K3 serta melakukan kegiatan peninjauan ulang pada kegiatan tersebut.

\section{Komitmen dan Kebijakan}

a. Membuat struktur Pembina Keselamatan dan kesehatan kerja dengan susunan yang terlampir dengan keputusan ini

b. Dalam melaksanakan tugasnya panitia pembina keselamatan dan kesehatan kerja (P2K3) bertanggung jawab langsung kepada Direktur.

Berdasarkan hasil penelitian pada variabel komitmen dan kebijakan pada tim K3 atau panitia pembina keselamatan dan kesehatan kerja di rumah sakit dari 16 responden diperoleh hasil yang kurang mengetahui tentang komitmen dan kebijakan keselamatan dan kesehatan kerja dengan kurang baik sebanyak 11 orang $(68,75 \%)$.

Hasil tersebut di atas menggambarkan bahwa di rumah sakit dalam bidang K3 tidak terlaksana dengan baik, karena hal tersebut di sebabkan oleh tidak adanya tenaga ahli di bidang K3 itu sendiri. Keberadaan organisasi K3 tidak diketahui oleh semua karyawan yang berada di RSUD karena kurangnya sosialisasi sehingga komitmen dan kebijakan yang ada dalam sistem manajemen keselamatan dan kesehatan kerja kurang di pahami oleh karyawan. Agar seluruh pihak RS mengetahui dan melaksanakan hal tersebut maka perlu dilakukan sosialisasi secara rutin atau berkala.

2. Perencanaan K3

a. Menyusun rencana kerja tahunan (TOR) P2K3

b. Merencanakan kebutuhan tenaga, sarana dan prasarana serta anggaran yang diperlukan dalam kegiatan P2K3

c. Mengatur kegiatan dan mengkoordinasikan kegiatan pada masing-masing program kerja (Pokja)

d. Membuat dokumen rencana kerja P2K3

e. Membuat dokumen kebutuhan tenaga, saran dan prasarana serta anggaran yang diperlukan dalam kegiatan P2K3

f. Mendokumenkan kegiatan pada masing-masing pokja

g. Mempersiapkan dan membuat notulen pada pertemuan berkala, bulanan, insidentill dengan anggota P2K3 atau dengan unit-unit yang ada di Rumah Sakit.

h. Membuat dokumen laporan kegiatan P2K3 setiap bulan

Berdasarkan hasil penelitian pada variabel perencanaan pada tim K3 dan P2K3 RSUD Dr.H.Moh.Anwar dari 16 responden diperoleh hasil responden yang kurang mengetahui tentang perencanaan keselamatan dan kesehatan kerja dengan jumlah 7 reponden $(43,75 \%)$. Hasil tersebut di atas menggambarkan bahwa SMK3 RS dalam bidang perencanaan yang meliputi identifikasi bahaya, penilaian dan pengendalian resiko sudah ada akan tetapi belum terlaksana dengan baik karena kurangnya koordinasi yang baik dari P2K3 untuk mengevaluasi kinerja keberhasilan perencanaan penerapan K3.

\section{Penerapan K3}

a. Mengawasi upaya perlindungan keselamatan kerja di lingkungan rumah sakit

b. Melakukan pengawasan terhadap penerapan alat pelindung diri (APD)

c. Melakukan pengawasan terhadap bahan beracun dan berbahaya (B3)

d. Melakukan pemeriksaan kesehatan bagi calon pegawai / calon karyawan yang akan bekerja 
e. Melakukan pemeriksaan kesehatan berkala minimal 1 kali dalam setahun untuk semua karyawan.

f. Melakukan program vaksinasi / pengobatan / perawatan untuk karyawan yang menderita sakit.

g. Melakukan pengawasan aspek sanitasi

h. Melakukan pengawasan sistem kerja laundry dari sisi keselamatan dan kesehatan kerja

i. Melakukan pengawasan terhadap pengendalian dampak lingkungan (Dalin)

j. Melakukan pengawasan terhadap penerapan CSSD/seterilisasi santral

k. Melakukan pengawasan terhadap sarana dan prasarana

1. Melakukan pengawasan dan penanggulangan terhadap bahaya kebakaran

m. Melakukan pengawasan dan penanggulangan bahaya petir

n. Melakukan pengawasan dan penanggulangan bahaya listrik

o. Melakukan pengawasan dan penanggulangan bahaya ditempat parkir.

Berdasarkan hasil penelitian pada variabel penerapan pada tim K3 atau P2K3 dari 16 diperoleh hasil yang kurang mengetahui tentang penerapan keselamatan dan kesehatan kerja berjumlah 7 responden $(43,75 \%)$.

Hal tersebut diatas menjelaskan bahwa masih banyak yang kurang mengetahui tentang penerapan SMK3 RS sehingga tujuan untuk mencapai Zero accident dengan upaya penanggulangan bahaya potensial yang mengancam jiwa seperti adanya pemeriksaan kesehatan secara berkala serta pemeriksaan laboratorium. Pemantauan kesehatan lingkungan, pemeriksaan yang dilakukan oleh pihak sanitasi dan BBTKL, serta Pencatatan dan pelaporan insiden kecelakaan kerja di rumah sakit yang dilakukan jika terjadi insiden saja masih kurang terlaksana dengan baik karena kurangnya sarana komunikasi yang baik antara tenaga kerja dan pihak tenaga kerja, serta tidak tersedianya sarana yang baik untuk menerapkan SMK3 RS.

\section{Pengukuran dan Evaluasi}

a. Membuat dokumen awal untuk calon tenga kerja / calon karyawan yang akan bekerja

b. Melakukan pengawasan setiap bulan dan membuat laporan setiap selesai melakukan pengawasan kepada Direktur

c. Memberikan masukan / rekomendasi kepada Direktur terhadap ketentuan yang harus diikuti oleh pengawasan lain yang akan melakukan kegiatan / bekerja di dalam lingkungan RSUD Dr. H.Moh.Anwar Sumenep terkait dengan keselamatan dan kesehatan kerja (K3)

Berdasarkan hasil penelitian pada variabel Pengukuran dan Evaluasi pada tim K3 atau P2K3 RS dari 16 responden diperoleh hasil yang kurang mengetahui tentang pengukuran dan evaluasi K3 sebanyak 8 orang (50\%).

Hal tersebut di atas dapat menggambarkan bahwa pengukuran dan evaluasi penerapan SMK3 RS yang seharusnya dilakukan secara konsisten yaitu dengan adanya pemeriksaan yang dilakukan oleh masing-masing pokja, serta dilakukan penyelidikan sebab insiden dengan melakukan cek laboratorium dan perawatan secara berkala belum terlaksana dengan baik, hal ini di sebabkan oleh kurangnya sosialisasi kepada seluruh pihak rumah sakit sebagai tindakan perbaikan dan pencegahan secara sistematis dan efektif.

\section{Tinjauan Ulang K3}

a. Melaporkan kegiatan P2K3 setiap bulan kepada direktur

b. Membuat laporan 1 (satu) kali dalam tiga bulan kepada menteri tenaga kerja dan transmigrasi Republik Indonesia melalui Dinas Tenaga Kerja provinsi \& ditembuskan kepada Dinas Tenaga Kerja Kabupaten/Kota.

c. Mengadakan pertemuan berkala, bulanan, insidentill dengan anggota $\mathrm{P} 2 \mathrm{~K} 3$ atau dengan unit-unit yang ada di Rumah Sakit

d. Mengarsipkan semua dokumen P2K3.

Berdasarkan hasil penelitian pada variabel Tinjauan Ulang pada tim K3 atau P2K3 dari 16 responden diperoleh hasil yang mengetahui tentang Tinjauan Ulang K3 keselamatan dan kesehatan kerja dengan kriteria cukup sebanyak 9 orang $(56,25 \%)$.

Hal tersebut di atas menggambarkan bahwa tinjauan ulang oleh $\mathrm{P} 2 \mathrm{~K} 3$ belum terlaksana dengan baik, seperti sterilisasi, kalibrasi alat serta mengecek ulang yang tidak sesuai dengan dengan kebijakankebijakan K3. Karena tinjauan tersebut tidak dilakukan secara berkala dan teratur sehingga hal ini dapat menghambat adanya perbaikan

\section{KESIMPULAN}

1. Penilaian pada variabel kebijakan dan komitmen penerapan sistem manajemen keselamatan dan kesehatan kerja sudah terlaksana dalam pelaksanaannya P2K3 bertanggung jawab langsung kepada direkur. Responden yang mengetahui tentang komitmen dan kebijakan dengan kriteria kurang sebesar 68,75\%.

2. Penilaian pada variabel perencanaan sudah terlaksana dengan adanya susunan rencana kerja tahunan, rencana sarana dan prasarana serta anggaran untuk tim K3, responden yang mengetahui tentang dengan kriteria kurang sebesar $43,75 \%$.

3. Penilaian pada variabel penerapan sudah terlaksana dengan adanya pengawasan, pemeriksaan, dan perlindungan terhadap keselamatan dan kesehatan kerja, responden atau yang mengetahui tentang penerapan dengan kriteria kurang sebesar 43,75\% 
4. Penilaian pada variabel Pengukuran dan Evaluasi sudah terlaksana dengan adanya pembuatan dokumen awal untuk calon tenaga kerja, rekomendasi kepada direktur terhadap ketentuan yang harus diikuti oleh tenaga kerja lain.Responden yang mengetahui tentang Pengukuran dan Evaluasi dengan kriteria kurang sebesar 50\%.

5. Penilaian pada variabel Tinjauan Ulang sudah terlaksana dengan adanya laporan kegiatan $\mathrm{P} 2 \mathrm{~K} 3$ kepada direktur, pengadaan rapat secara berkala, serta pengarsipan semua dokumen $\mathrm{P} 2 \mathrm{~K} 3$. Tenaga kerja atau P2K3 yang mengetahui tentang tinjauan ulang $\mathrm{K} 3$ dengan kriteria kurang sebesar $56,25 \%$.

6. Hasil penelitian di dapatkan bahwa tingkat kecelakaan kerja dengan jumlah 81 tenaga kerja dengan tingkat kecelakaan kerja tinggi sebanyak 29 orang $(35,8 \%)$

\section{DAFTAR PUSTAKA}

Anonymous, Keputusan Menteri Kesehatan Republik Indonesia Nomor 1087/MENKES/VIII/2010 tentang Standar Kesehatan dan Keselamatan Kerja di Rumah Sakit

Anonymous, Peraturan Menteri Kesehatan Republik Indonesia Nomor 66 Tahun 2016 Tentang Keselamatan Dan Kesehatan Kerja Rumah Sakit

Abdul Rohman, 2017 Pengaruh keselamatan dan kesehatan kerja $(k 3)$ terhadap produktivitas kerja karyawan Pada pt. Andala auto global tangerang. Universitas Pamulang, Tangerang Selatan

Kun Dwi Apriliawati, Ekawati dan Bina Kurniawan, 2017 Efektivitas Pelaksanaan Manajemen Organisasi Keselamatan Dan Kesehatan Kerja Rumah Sakit (K3 Rs) Di Rumah Sakit X Semarang
Suardi dan Rudi,2007.Sistem Manajemen Keselamatan Kerja,panduan penerapan berdasarkan OHSAS 18001 dan Permenaker 05/1996. Jakarta Pusat

Ridley John,2008 Kesehatan dan Keselamatan Kerja. Jakarta

Santoso Gempur, 2004. Manajemen Keselamatan dan Kesehatan Kerja. Jakarta

Sabarguna.S.Boy, 2003. Manajemen Operasional Rumah Sakit, Konsorsium Rumah Sakit Islam Jateng-Yogyakarta

Ramli Soehatman,2009. Sistem Manajemen Keselamatan dan Kesehatan Kerja OHSAS 18001. Jakarta, Dian Rakyat.

Munijaya Gde, 2011. Manajemen Kesehatan.Jakarta

Peraturan Direktur Rumah Sakit Umum Daerah Dr.H.Moh.Anwar Kabupaten Sumenep, Nomor :188/ 931/ $432.210 / 2013$

Puspitasari Ika,2008. Penerapan Sistem Manajemen Keselamatan dan Kesehatan Kerja di Rumah Sakit Haji Surabaya tahun 2011, Hal 18

Salawati Liza, 2009. Hubungan Perilaku, Manajemen Keselamatan dan Kesehatan kerja dengan terjadinya kecelakaan kerja di laboratorium patologi Klinik Rumah Sakit Umum Zainoel Abidin Banda Aceh, Hal 4.

Suma'mur,2009.Higiene Perusahaan dan Kesehatan Kerja (Hiperkes).Jakarta 